To be published in the Proceedings of the "Inteinulional

$$
10 N F-34091103-3-4
$$

Workshop on Coherent and collective Properties in the

Interaction of Polativistic Beams and Electromagnetic

Radiation", Como, Italy, Sept. 13-16, 1984

SUMALRI OF TEE WORKING GROUP ON FEL TFLORY*

BNL -36080

\title{
c. Pellegrint
}

DE85 009769

Mational Syochrotron Light Source

Brookhaven Natíonal Laboratory, Cpton, New York 11973

\section{Introduction}

The working group on FEL theory dedicated wont of 1ts discussions to toplcs relevant to the high gain regine in a free electron laser. In addition the area of incerst was mainiy restricted to FELs for the production of XWV radiation ( $(1000 \mathrm{~A})$. A list of the topics that were felt to be relevant is:

1) characterization of the FEL high gain regiwe;

2) the amplified spontaneous enission sorle of operation (ASE);

3) superradiance in FELa;

4) diffraction effects for high galn FEL;

5) notse and startup;

6) Coherence properties of the radiation for the ASE and supradiant FELS.

Other 1mportant problems, like for Instance quantum effects for short wavelength FELs, had been considered in the Brookhaven Worksthop on Free Electron Generation of RUV Coherent Radiation; a sumary of the discusstons held at that meeting can be found in reference $\mathbb{1}$.

Because of the 11mited time avaliable it was not possible to discuss and reach a consensus on all of these probleas. For sowe of them, in particular for topics 5 and 6 , it was only possible to conclude that nore work is needed. On topics 1 to 4 wuch work has been done during the last year or two and new resuits are reported in papers appearing in these proceedings ${ }^{-5}$

and w11 be summarized here.

sWork supported by the U.S. Department of Energy tParc1c1pants: R. Bonifactio, F. Cagagrande, G. Dattol1, I. Doscolo, W.J. F1rth, J. Goldstein, S. Nhelfets, G. F. Hoore, MoR. Masulio, C. Peilegrini, P. Sprangle, H. Takeda, J. S. Thurtele. 


\section{Hish raln refine}

The energy transfer betwees the electron bea and the rediation in an FEL can be enhanced by a collective Instabli1ty producing an exponential

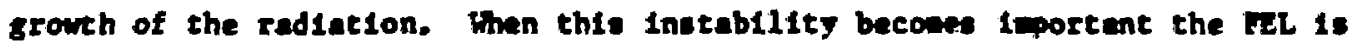
ould to operate in the Hugh Galn Begine. The existence of this regtee is very Important for the Fut operation in the XVV regton where do not have optical comonents with ufficlently high refiectrity and well absorption. The ILL perforance can be characterized by one paraneter ${ }^{6}$, $p:$

$$
p=\left(x \Omega_{p} / 4 \omega_{0}\right)^{2 / 3}
$$

where the plasns and undulator frequencies are

$$
\begin{aligned}
& \Omega_{p}=\left(4 \pi r e c^{2} n_{0} / \gamma^{3}\right)^{1 / 2} \\
& \omega_{0}=2 \pi c / \lambda_{0} .
\end{aligned}
$$

The quantitles introduced in (1), (2), (3) are: the classical electron radits $r_{e}$; the 11ght velocity $c$; the elestron bean density $n_{0}$; the electron energy, $\gamma$, in unit of rest mass $n c^{2}$; the undulator period, $\lambda_{0}$ sagnetic field, $B_{0}$, and paraneter $K=e B_{0} \lambda_{0} / 2 \pi m c^{2}$. We w11 also use the radiation wavelength, $\lambda$, related to the electron resonanc energy, $\gamma_{R}$ ty

$$
\lambda=\lambda_{0}\left(1+k^{2}\right) / 2 \gamma_{R}^{2}
$$

Using the parmeter rho, and asuaing zero detuning, 1.e. $Y=Y_{R}$ the gain per unit undulator perlod is given by

$$
G_{p}=3^{1 / 2} 2 \pi p
$$

Equation (4) is val1d as long as the condition that the electron boan relative energy spread, $\sigma_{E}$, be leas than is is satiofled. 
The evolution of the radiation field aplitude, $A_{3}$ or of the electron bea bunching, 1s described by an exponential if the systen starte froa a onal intefal field or an equivalent notse level:

$$
A-A_{0} \exp \left(n_{0}, \cdot\right)
$$

where $N_{w}$ 1. the nuber of undulator perlods. The high gain regtae is defined by the condition

$$
G_{p} N_{w}>1
$$

The exponential growth slows dow and saturates when the electrons are crapped in the potential well forwed by the radiation. This condition can be approximately extinated by requiring that the electron osciliation period in the vave potential well be of the order of the exponential grouth rate. This gives for the wave electric fleld amplitude value

$$
E_{S}=\mathrm{CB}_{0}(2 \mathrm{Dr} / \mathrm{K})^{2}
$$

Using (7) we can calculate the radiation fleld peak power, $P_{L}$, at saturation, obtaining the simple result that $P_{\mathbb{L}} 1 s$ simply o tmes the electron beam peak power, $P_{E}=w c^{2} I_{p}$, where $I_{p}$ is the electron peak current:

$$
P_{I}=P P_{B}
$$

Hence, $P$ measures also the efficlency of energy transfer from the electron beam to the radiation fleld. Notice also that at saturation the radiation power, given by (B), Is proportional to $\mathrm{N}_{e}^{4 / 3}$, $\mathrm{N}_{e}$ beling the nuber of electrons.

3. The Amplified Spontaneous Emission mode of operation of a TEL

If we let one electron traverse an undulztor, it w11 produce spontaneous undulator radiation. What happens when we consider an electron 
bew with te particles in 1t? In doing the su of the field aplitude, we wat attribute to each elcctron a phae factor exp $\left(1 \phi_{0}\right)$, to being the Initial phase of the electron relative to the wre. To deternine the dietribution of the pheses we met etudy the electron longttudinal denstty detribution on the ocele of the rediacion wavelength. For a bee with a unifors: longitudinal density detribution, the su over the InItial phase factors would give zero, and no radiation would be oberved. A random distribution of the phases, like is observed in a real bean, gives an Intensity proportional to the number of electrons. Ne.

In doing this calculation one aswes that the beas intensity is swall and that as a conseouence also the intensity of the radiation is sail. 10 that the radiation field does not influence in any significant way the particle dynascs. If we let the been intensity grow, or, alternatively we consider a very long undulator, this condition is violated and we ans study the evolution of the system, atarting from nolse, including the action of the radiation field on the particle motion. This leads to arpiffication of the radiaclon, and to the Amplified Spontaneous Enlssion (ASE), mode of operation 1n which $P_{L}-N_{e} 4 / 3$. The study of the ASE has been done in ref. 6,7 , B. To be in this sode one mast clearly satisfy the condition (6) for high gain. Furtherwore to reach saturation in this mode one needs a value of the exponential galn factor, $G_{p} N_{w}$, of the order of 10 , 16 the bean has an energy spread sanller than $p$.

The ma1n advantage of operating an FEL in the ASE mode, as cospared to an FEL osciliator using an optical cavity, is that one does not need any. optical elewents. Th1s advantage 13 important at short wavelength, where 
good Ifrrors are not avallable. Compred to a TOK the ASE can provide a ach higher efficiency of energy transfer from the electrons to the radiation. The dieadvantage of the ASE is that 1t ragulies a large value of the gain. $\mathrm{C}_{\mathrm{p}} \mathrm{H}_{\mathrm{w}}-10$, while for an osclilat or $1 \mathrm{t}$ is sufficlent to have a gatn on the order of one and for TOK lese than one.

\section{Superradiance in FEL}

As we discussed in the previous sections the animum laser power oitalnable in an FTL is $11 \mathrm{mited}$ by saturation effects and is proportional to $\mathrm{N}_{\mathrm{e}}^{3 / 4}$. This is correct under the condltion that the undulator has constant pe:lod and magnetic fleld and that sifpage effects are negligible.

Taperting of the undulator ${ }^{9}$ is a way to remove thls 110itation. Another possibility has been discussed at this seet1ng by Bontfacto and Casagrande ${ }^{3}$. They study the ASE when the electron bunch is shorter than the silppage distance $s=\lambda N_{w} ;$ in this case some of the radlation produced Hill escape fron the bunch during the transversal of the undulator. In this way one can remove radiation from the bunch and avoid saturation. On the other hand the bunch must have a large enough density to be in he high gals regime, so one can define a region in the parameter space of the FEL where ASE is not limited by saturation and the radiation intensity can grow up to the point where it is proportional to the square of the electron number.

This supertadiant regime is very exclting not only as an interesting asfect of the FEL physics but also because 1t can provide the capability of producing very short radiation pulses with large peak power. 


\section{Diffraction gffects for hifh gain Fet}

The expreasion for the gain given in Sactirn 2, is valid only in the 1int of a one disensional problen, wen the rediation is described by a plane vave.

Uing claple geonetrical opt1ce, for en elestron bean of radiue "a". radiation wavelength $\lambda$, radiation walst $w_{0}$ and undulator length $I_{w}$, we can expect diffraction effects co be important wen

$$
\frac{\lambda}{w_{0}} L_{w}>
$$

In most cases one can assume a $w_{0}$ and introduce the Railelgh range $z_{R}=$ $\pi a^{2} / \lambda$. The condition for diffraction to be negligible and the one dimenolonal theoty to be apflicable can then be written as

$$
\frac{Z_{R}}{L_{W}}>1
$$

For small ealttance bears and long undulator, both needed for high gain, this conditon can be easily violated.

This problem has been studfed in the papers by Moore ${ }^{4}$ and by Scharlenann, Sessier and Hurtele ${ }^{5}$ presented at this weeting. Thes authors show that the electron bean can produce a guiding action on the radiation, similar to that provided by an optical fiber. The electron bean has an index of refraction, $n$, whose real and luaginary parts are related, in the one dimensional oodel, to the phase and amplitude derivative of the radiation field and thus to the beam bunching. The real and laaginary part of the Index of refraction describes refractive guiding when $\operatorname{Re}(n)>1$, and gain focusing where In (n) >1. For an FeL both terms are present and can play a dominant role in different conditions. 
A ctople and qualitative of describing this effect is to introduce an "effective Ralleigh range", $z_{R}^{*}$, larger than the geonetrical optica $z_{R^{*}}$ The ratio $z_{R}^{*} / z_{R}$ is a measure of the bea guiding action, and is again given by the FEL parameter $P$ :

$$
z_{R}^{*} / z_{R}-4 \pi \rho N_{w}
$$

One can rewrite the condition (10) substituting $Z_{R}^{*}$ to $z_{R}$, as

$$
4 \pi p \frac{Z_{K}}{\lambda_{w}}>1
$$

This condition can be used to estimate the applicability of the one dimensional model. If (12) 1s vlolated diffraction effects are important and tha gain of the systes is less than that given in the one dimensional wodel. 


\section{References}

1. W. B., Colson, Sumary Discussion; Thebretical Apects of IUV Iree Electron Laser, In Free Electron Laer Ceneration of Bxtrane Ultraviolet Coherent Radietion, J. M. J. Madey and C. Pellegrint, Ede., Meriean Inetitute of Physics Conf. Proc. Mo. 118 (1983), p. 260.

2. P. Sprangle, C. M. Tang and C. H. Roberaon, Collective Effecto in Free Electron Laer, paper in these proceedings.

3. R. Bonifacto and F. Casagrande, The superrad1ant Reg1e of a Freelectron Laser, paper in these proceedings.

4. G. T. Moore, The Algh Gain Reglme of the Free Electron Laser, paper in these proceed1ngs.

5. E. T. Scharlemann, A. M. Sessler and J. F. Wurtele, optical Gulding of a Free Electron laser, paper in these proceedings.

6. R. Bon1fac10, C. Pellegrin1 and L. M. Narduce1, Opt1es Cowm., 50, 373 (19.84).

7. J. B. Murphy, C. Pellegrini and R. Bonifacto, Collectlve Instability of a Free Electron Laser Incuding Space Charge and Hermonics, to be published In Optics Comm.

8. J. B. Murphy and C. Pellegrin1, J. Opt. Soc. Amerlca B, 2, 259 (1985).

9. N. M. Kroll, P. I. Morton and M. N. Rosenbluth, IEEE Journ. Ouant. Electr. ㅁ-17, $1436(1981)$.

\section{DISCLAIMER}

This repcrt was prepared as an wocount of work epomoned by an sency of the United States Covernment. Neither the United Stutes Covernmeat nor any insowcy thereof, tror any of their

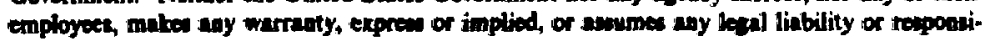
bility for the accuracy, completenem, or udefines of any informetion, eppuratus, product, or proces diecloned, or repreceits that its we mouls aot infrine privately owned rights. Refer-

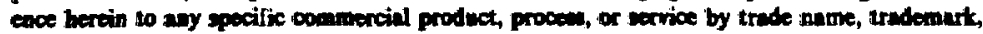

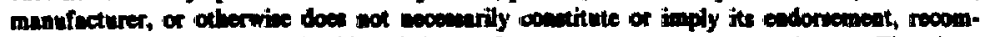
meadation, or fawories by the United Sunve Gowernaest of any agocy thereof. The view

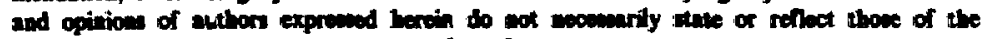
Usited States Gowernent or acy apacy thereot. 